\title{
Design for End-of-Life Value Framework for Vehicles Design and Development Process
}

\author{
Muhamad Zameri Mat Saman \\ Department of Manufacturing and Industrial Engineering, Faculty of Mechanical Engineering \\ University Teknologi Malaysia, 81310 UTM Johor Bahru, Johor, Malaysia \\ Tel: 60-7-553-4833 E-mail: zameri@fkm.utm.my \\ Norhayati Zakuan \\ Department of Management, Faculty of Management and Human Resource Development \\ University Teknologi Malaysia, 81310 UTM Johor Bahru, Johor, Malaysia \\ Tel: 60-7-553-4663 E-mail: norhayatimz@utm.my \\ Gordon Blount \\ Faculty of Engineering nad Computing, Coventry University, United Kingdom
}

$\begin{array}{lc}\text { Received: September 5, } 2011 & \text { Accepted: February 20, } 2012 \quad \text { Published: March 1, } 2012 \\ \text { doi:10.5539/jsd.v5n3p95 } & \text { URL: http://dx.doi.org/10.5539/jsd.v5n3p95 }\end{array}$

The research is financed by Research University Grant, Universiti Teknologi Malaysia

\begin{abstract}
Nowadays, with growing public concern over environmental issues, companies are under pressure from government and society to reduce the impact of their activities. Based on that, in the early 1990's the European Union identified End-of-Life Vehicle (ELV) as a priority waste stream and a directive was introduced to protect the environment. Automotive companies are being pushed by environmental awareness and legislation to recycle, remanufacture and reuse the components at the end of life and also to reduce the quantity of manufacturing waste generated. Within this scenario, a design tool is needed for automotive design processes to fulfil the requirement of the European Union Directive on End-of-Life Vehicles. Besides that, the role of design in modern manufacturing is becoming even more important with companies adopting design tools as profit generating business elements especially for the automotive recycling or dismantling companies. Hence, this paper discusses a Design for End-of-Life (DFEL) Value framework for the vehicle design and development process. The framework described in this paper consists of 4 main steps: investigation of the current situation, Recycling Function Deployment (RFD) analysis for value and cost, characteristics selection and lastly decision for detail design. RFD is a new idea based on the concept of Quality Function Deployment (QFD). It is believed that the adoption of DFEL Value concept can help the designer to design the products to fulfil the end-of-life requirements. This paper concludes with a discussion and further direction for this research.

Keywords: Recycling function deployment, Value analysis, Vehicle design, Automotive recycling, EU directive on End-of Life-Vehicles

\section{Introduction}

Throughout the last two decades the demand for safety, quality and reduced prices for European cars created a decrease in the use of recyclable materials. This resulted in increasing amounts of End-of-Life Vehicles (ELV) components going to landfill. So in the early 1990's the European Union (EU) identified ELV as a priority waste stream and a directive was introduced. Furthermore, as it is move forward into 21 st century, the automotive industry is turning its attention to the issues of environmental friendly vehicle in order to respond to the implementation of EU Directive on ELV.
\end{abstract}


The EU draft on ELV outlined that car manufacturers must reuse or recover $85 \%$ of ELV by 2006 . At least $80 \%$ of that weight must be reused or recycled while up to $5 \%$ can be dealt with through other recovery operations such as incineration. This target increases to $95 \%$ by 2015 and at least $85 \%$ of that weight must be reused or recycled (Goodfellow, 2002; Afrinaldi et al., 2010).

The introduction of the directive will affect all players involved in the management of ELV in terms operational strategy, infrastructure and financial investment and the most important thing is a vehicle design and development process. The whole structure of automotive industries is expected to change with more focuses to designing in relation to recycling aspects. The traditional design process will become more advanced, as legislation demands the removal of all hazardous liquids and components. Some form of plastics, rubber and glass recovery is necessary, either during the dismantling phase or during the separation process. This is the big challenges to the vehicle designers.

In this scenario, a dedicated framework is needed for automotive design recyclability assessment to fulfil the requirement of EU Directive on ELV and at the same time to improve the design of the vehicle components in order to increase the value at end of life. The paper begins with a short description of literature in this area and follows this with a detailed explanation of the proposed framework. After that, the paper presents a case study in order to demonstrate and validate the proposed framework. Lastly, the results are discussed and conclusions drawn with recommendations for further research.

\section{Literature Review}

\subsection{Design Requirements for ELV}

In recent years, environment issues and sustainability have become main items of debates in the automotive industry. The elements of environment and recycling will become even more important in the vehicle development process in the near future. These elements have to be considered more seriously at the early design and construction of the vehicle.

With the trend toward green design, vehicle manufacturers are faced with the challenge of improving vehicle recyclability while reducing product cost and increasing the value at end of life. To cope with these challenges, the vehicle design and development process has to be integrated with disassembly and the recycling consideration. Moreover, according to Ferrao and Amaral (2006), recycling activity is profitable within a large range of disassembly levels and the profits increase for the higher disassembly rates. Besides that, there are four main end-of-life requirements that vehicle designers have to consider during the vehicle design and development process; design consideration, material used, economic aspect and directive requirements.

\subsubsection{Design Consideration}

According to Erkki Liikanen (Kimberley \& Glover, 2004), the Commissioner with responsibility for enterprise policy for BMW, it is essential for the vehicle manufacturers to incorporate the recycling aspect at the early development stage in producing new vehicles. This is in order to demonstrate its commitment to producing more environmental friendly vehicles, to protect the environment and to fulfil the EU Directive on ELV, even if this results in increased production costs.

According to Joshi, Venkatachalam, and Jawahir (2006), shifting from the 3R concept (reduce, reuse, recycle) to the $6 \mathrm{R}$ concept (reduce, remanufacture, reuse, recover, recycle, redesign) in vehicle design stage may result saving gains for both manufacturers and consumers. Figure 1 describes this concept.

It is clear that design consideration is a main element in the ELV concept. Design decisions on the part of vehicle designers can make automotive recycling a safer and more efficient process by eliminating the presence of hazardous substances. It also can make them more easily dismantled and enable components to be remanufactured several times. This later aspect is because the various vehicle parts can be recycled in a closed-loop. Closed-loop recycling is a concept where a product is remanufactured into the same type of product without the addition of any first-use materials. In this case, Alting and Jorgensen (1993) was the first to introduce the recycling concept within a life cycle design concept. This concept is integration between design need, design development, distribution, usage and also disposal and recycling. These are considered simultaneously at each stage of the design process.

It is hopes that design for recycling, dismantling and environment are becoming an essential aspect of modern automotive industry and their consideration has become a more important elements in the vehicle design and development process. 


\subsubsection{Material Used}

The accelerating change in materials composition (for example the increasing of the fraction of plastic and aluminium) of modern vehicle can create new problems in the recycling process of ELV. Recycling of plastic is very difficult when it is present in small parts or attached to another material. Similarly, recycling of aluminium is not straightforward because it is normally present in the form of alloys. Based on that scenario, material choice is one of the key elements in vehicle design in order to make the concept of ELV successfully implemented. This is basically because the different materials have a different technique of disassembly and recycling.

Plastic contributes around $9 \%$ of the weight of an ELV and this is increasing as vehicle manufacturers continue to develop lightweight vehicles to improve fuel efficiency (DTI Report, 2003). The recycling rate of plastics needs to be improved because most of the plastic material from an ELV arises at the shredder as shredder fluff. Furthermore, the plastic materials are very difficult to extract for recycling unless they can be removed prior to shredding but this normally is costly unless easy removal is part of the original design.

Mercedes Magazine (Spring, 2002), reported that they have taken over 18 months to analyse thousands of processes, components and materials relating to the end of life situation especially to reduce the impact on the environment. They started the process at the extraction and transportation of the new materials to the subsequent processes used to produce steel, aluminium, plastic and the vehicle components. For instance, they considered the use of lightweight materials (eg. aluminium or magnesium) for energy consumption used in manufacture and the potential of vehicle fuel saving. The production of aluminium from alumina using low emission energy sources (eg. natural gas) can make a significant environmental contribution.

Moreover, EU Directive 2005/673/EC on ELV (2005) stated that certain materials and components containing lead, mercury, cadmium or hexavalent chromium should be exempt or continue to be exempt from the prohibition, since the use of these substances in those specific materials and components is still unavoidable. In some cases it is appropriate to review the expiry date of these exemptions in order to assess whether the use of the prohibited substances is still unavoidable in the future.

It is clear that the right material selection for the vehicle components is an important aspect in the vehicle design. The use of recycled materials is increasingly important as product take back and producer responsibility legislation are implemented.

\subsubsection{Economic Aspect}

Automotive disassembly and recycling were became to be of high ecological and economic important. To comply with the increasingly tightening automotive recycling legislation and to make the automotive recycling business economically competitive, the elements of environmental and recycling have to be considered more seriously at the design process (Tzafestas et al., 1997). Therefore, according to Kwak, Hong and Cho (2009) and Hassan et al. (2011), in order to enable economic disassembly and recycling which also conform to environmental regulations, designers should make a proper decision on product architecture. In this context, it is in industry's interest to develop a design method or a tool for improving product architectures. But sometimes, the decision made by vehicle designers in order to fulfil these requirements can give a negative impact on the vehicle manufacturers especially in terms of manufacturing cost. So, this is the conflict between these two parties.

\subsubsection{Directive Requirements}

The new movement for improved vehicle recycling has its origin in the EU Directive on ELV (EU Directive on ELV, 2000). This directive was devised mainly to avoid the car crisis and motivated by environmental consciousness. Design decisions on car manufacturing are steered by this directive to areas such as the use of environmentally friendly materials and also to design vehicles with reuse, remanufacturing and recycling in mind.

\subsection{Current Development Tools on Assessment of ELV}

Basically, there are two factors to influence the development tools for assessment of ELV; design process and financial judgement for recycling process. In recent years, research activity related to the recycling activities and also environmental aspect has been increased dramatically. This is because recycling activities are the key components of EU Directive on ELV. Based on that, to ensure excellent vehicle design, the right design tools and techniques need to be established. For this paper, a review encompassed several design tools and techniques must be undertaken. For this paper, the review encompassed several design tools and techniques that related to the Quality Function Deployment (QFD) and value analysis. Basically, these two techniques is a core for the proposed framework. 


\subsubsection{Quality Function Deployment (QFD)}

Halog et al. (2000) propose a modified version of QFD, called House of Ecology (HOE), for optimum environmental performance improvement. They formulate the mathematical model for cost effective environmental performance improvement and also derive principles for emission reduction. The result of the study shows the substances that contribute critically to the deterioration of the environment based on their impact potentials. Based on that, the cost could be allocated effectively.

Santos-Reyes and Lawlor-Wright (2001) presents a design for the environment methodology to support an environmental management system. This is a conceptual approach for integrating environmental concerns at an early product design phase using QFD concept, called Environmental House of Quality (EHOQ). It consists of four stages; abstraction, modelling, manipulation and evaluation. The main target is to provide an organised process that may allow designers to identify and understand environmental needs, how to satisfy the needs and how the improvement options can be measured in the design process. The outcome of this study may help to explain a product's life cycle environmental impact and to measure the product environmental performance.

The latest improvement was reported by Masui et al. (2003). They present a methodology for applying QFD for environmentally conscious design in the early stages of product development. This methodology has been developed by incorporating environmental aspects into QFD in order to handle the environmental requirements. The proposed methodology called QFD for Environment (QFDE). It consists the four phases. Phases I and II are identification of the components that should be focussed and Phases III and IV will be used to examine the possibility of design improvement for each component and the improvement effects of the design changes.

In relation to that, the most important thing is a customer requirement. QFD takes the voice of the customer from the beginning of product development and development and deploys it throughout the firm. Through QFD, the voice of the customer aligns the company's resources to focus on maximising customer satisfaction.

\subsubsection{Value Analysis}

Generally, there are many value analysis models that had been developed such as those reported by Tipnis (1991). But with introducing the concept of Life Cycle Costing (LCC), in relation with EOL situation, some of the conventional models need to be reconstructed in order to fulfil the requirements of EOL situation in areas such as environmental aspects, disassembly and recycling activities.

In the early 1990's, several value analysis models for recycling activities have been developd. Dieffenbach and Mascarin (1993), examine the costs and value associated with the present vehicle recycling infrastructure using a technique called Technical Cost Modelling. This is a computer spreadsheet technique used by IBIS Associates for the simulation of process costs. Using this technique, several alternatives are developed for the recovery of plastics from scrapped vehicles based on varying the material mixes of vehicles. This is to determine how best to recover the plastic materials. This model can help the designer to design the components to be more recyclable.

Veerakamolmal and Gupta (1999) present the technique to analyse the efficiency of designing electronics products for the environment. The efficiency of each design is indicated using Design for Disassembly Index (DfDI) to measure the economic efficiency of the recycling process. This technique involves the analysis of the trade-off between the costs and benefits of end-of-life disassembly to find the combination of components that provides the optimum cost-benefit ratio for end-of-life retrieval. Mat Saman et al. (2010) noted about the benefit of disassembly. The cost considerations include the costs of disassembly (labour) and disposal, while the benefit is derived from the sale of recovered components and materials. The index offers designer with an important measure to help improve future design of products.

In 2003, development in this area was reported by Association of Plastics Manufacturers in Europe; called eco-efficiency analysis (APME Report, 2003). It is a useful tool to quantify and compare different recovery/recycling options with regards to their environment and economic aspects.

The result of the literature review shows that there is a need for the proper model for DFEL Value in order to successfully implement the EU Directive on ELV. This aspect must be considered and evaluated more rigorously in the early product design process. This scenario can help the automotive designers to design a more recyclable vehicle and economic viability of the recycling process.

\section{Study Methodology}

There are two concepts that facilitated the development of the DFEL Value concept. They are recycling function deployment (RFD) and value analysis. These two concepts are primarily developed to assist automotive designers to design a vehicle for EOL purposes however as a consequence it enables an investment decision for recycling 
facilities to be evaluated. The process will be start with the RFD analysis and followed by the value analysis. These two methodologies are interrelated to each other. The RFD analysis is intended to provide an organised process that allows designers to identify and understand the recyclability needs and how to measure recyclability in the design process. It also shows the components or parts that have a potential to improve the performance of design in terms of recycling.

Meanwhile, value analysis is a design assessment tool. As an environmental issues should be accountable throughout the whole life cycle of a product, i.e. its design, manufacture, use, service and its end-of-life. Hence, this new approach will enable automotive designers to assess the design of products for their technical and economic viability at end of life. It is illustrates an assessment of the reuse, recycling and recovery factors with dynamic and uncertain data. It argues that indicators from the analysis can be used for initial design assessment and also to inform the strategic development plans of the vehicles, infrastructures and spare part businesses.

It takes into account the impact of the EU Directive and the solution to enhance the recyclability and value of ELV. In the development process, several parameters in the product development process have been considered such as material types, joining techniques, product structure, environmental issues, economic consideration and also recycling technologies and facilities.

Basically, the structure of the DFEL Value methodology is a conceptual approach for integrating recyclability concern at an early product design phase as shown in Figure 2. This approach is intended to provide an organized process that allows designers to identify and understand the recyclability needs and how to measure recyclability during the design process.

\section{Development of Framework for DFEL Value}

Recycling Function Deployment (RFD) is a method for mapping and prioritising recycling needs into product development process to optimise ELV performance and meet EU Directive requirements. It reflects an integrated product development process but offers advantages by using a format and language understood by customers, in this case the recycling company and vehicle designer, who become part of the system design process.

In this case, a basic matrix for initial product planning uses the recycling requirements as input and translates it into technical requirements. The structure of the RFD methodology is also a conceptual approach for integrating recyclability concern at an early product design phase as shown in Figure 3. This approach is intended to provide an organised process that allows designers to identify and understand the recyclability needs and how to measure recyclability in the design process.

The inspiration for RFD came from the long established method of Quality Function Deployment (QFD) (Halog et al., 2001). RFD uses many of the concepts of QFD for the methodology.

In this concept, two types of RFD are proposed. There is RFD for revenue determination and RFD for cost determination. Each of these has two levels; Level 1 - Design for End-of-Life Value Requirements or Recycling Cost Factors versus Key Product Characteristics and Level 2 - Key Product Characteristics versus Parts or Components. These results are translated into Revenue-Cost ratios using the consideration from the absolute revenue and cost from Value Analysis. This is to identify which component or part has a potential improvement.

There are four steps in the proposed methodology as shown in Figure 3 above,

Step 1: Determine the DFEL Value or recycling cost requirements for the product

DFEL Value requirements (for revenue determination) are the factors that need to be fulfilled in order to determine the revenue generated from the recycling process. However, the recycling cost requirements (for cost determination) are the factors that need to be addressed in order to determine the cost for recycling process. Each factor will be compared with the typical product characteristics.

Step 2: Analyse the proposed strategy

Firstly, decide the importance rating for each requirements or factor. The importance rating is used to record how importance each requirement or benefit to the recycling company. Importance rating values were place on a 1 to 10 point scale. The higher the value, the more important was that DFEL Value or recycling cost requirement. Secondly, determine the relationship matrix. The relationship matrix is a main key in this process. The matrix is used to analyse how each key product characteristics will fulfill each DFEL Value requirement. In this section, each relationship cell represents a judgement of the strength of the linkage between a key product characteristic and DFEL Value requirement. The strength of linkage is named impact of revenue. There are four types of impact; high (9), medium (3), low (1) and not linked (0). These are the values conventionally used in QFD analyses. Lastly is determining the correlation matrix. In the classic QFD process, the interrelationship of each key product 
characteristic is referred to as the correlation matrix. In general applications, placing the symbols, + or - , representing positive and negative relationship between key product characteristic attributes indicates the nature of the interrelationship. In the proposed design tool, this factor was not used because it is not involved in any subsequent calculation. In QFD it is used by designers in determination of tradeoffs.

Step 3: Evaluate the proposed strategy in terms of product performance

The evaluation process is based on the revenue-cost ratios. This ratio represents the design performance for each component or part to fulfil the end-of-life value situation. The ratio 1 indicates that there is a close match between revenue and cost. Ratios higher than 1 indicate that the component or part has a good design with reference to recycling. Ratios lower than 1 suggests that component or part should be examined for design improvement.

Step 4: Recommend countermeasures from the proposed strategy

Based on the performance results, the framework provides a mechanism to check what the problem is with that particular component. When the designers know the weaknesses of those components, they can explore further to find out how to improve those components. This process can provide a clear direction to the automotive designers as to how those components should be developed.

The detail for revenue determination and cost determination are shown in Figure 4 below.

\section{Case Study, Results and Discussion}

\subsection{Case Study}

In order to demonstrate this model, ELV are introduced into the proposed methodology with the attention of investigating the optimal quantity of materials removed by the disassembler prior to shredder and also to maintain the maximum return for both the disassembler and shredder. Weight, cost and revenue are used as a common language to integrate the various levels of the analysis. In this case, the current design of the vehicle has been analysed as a case study. This vehicle was build from several materials but the main material is a ferrous metal. Figure 5 shows the detail diagram of product structure for the vehicle.

\subsection{Results}

\subsubsection{Revenue Determination}

The result for RFD analysis for revenue determination (Level 1) is shown in Figure 6. This result represents the impact of each product characteristic in generating the revenue at EOL for the current design of vehicle. As mentioned in Section 4, there are two factors are directly influence to the revenue generating at EOL situation; income from material sales and income from part or component sales. This shows that income from material sales contributes the most impact of the current design (61\%) and income from part or component sales (39\%).

In order to get those results, the most important thing is determination of impact value for all parameters. As discussed in Section 4, the impact values used are 9-3-1-0. The right allocation of impact value is very important because they are the key to the analysis. The advantage of this standard is that it can minimise the trivial and normalise the correlation between two factors such as in this case between DFEL Value requirements and key product characteristics.

This is to ensure that the requirements are given the appropriate amount of influence. The most important aspect here, normalisation, would properly represent the importance of key product characteristics in meeting the DFEL Value requirements. For example, currently the recovery of tyre (low value material) is very low and it is almost certain that all the tyres go to landfill. Thus, the impact value for tyre (income from material sales) for maximising the percentage of material recovered (material selection) was allocated as 0 under most requirements. That means, the contribution of tyre for revenue generating is very low. Meanwhile, high value component or part such as Electrical Items (income from part or component sales) gives a medium impact to the revenue generation because it contributes to the maximising of high value part (part or component design). So, in this case, the impact value was 3.

The Importance Rating values are additional key elements in this process. The most significance requirements will be given more attention. The Importance Rating will normally be determined by a group of people in the design team based on the fixed requirements such as legislation, customer, technology etc. For example, for the material selection of the vehicle, the most important requirement is almost always an environmental friendly material (rating decided as 9). 
Based on the results in Level 1, the fraction of score will be transferred into Level 2. All these values will be distributed according to the cell score compared to the total score for each characteristic. For example, ferrous part would be $0.61 \times(168 / 277)$ and equal to 0.37 as shown in Figure 7.

For the further analysis in Level 2, the relationship impact between the key product characteristics and the individual parts or components will be considered. The values that will be used are again 9-3-1-0. The determination of each value depends on the impact contribution to the revenue generating at the EOL. For example, the accessories can be categorised as a high value component. In this case, it is has a potential to be sold as a spare part (high revenue impact, 9). That means it can help to increase the potential to generate more revenue. However for those factors that have no relation, this is represented with 0 value. That means, those factors have no impact cost to each other.

These results represent the performance for each component in terms of percentage of revenue at EOL situation. The component that contributes most to the revenue was body (22.0\%) because most of the material used can be reprocessing and resold. Meanwhile, the lowest value was given by glass $(0.5 \%)$. Again, this is because of this type of material cannot currently be recycled.

\subsubsection{Cost Determination}

The results for RFD analysis for cost determination (Level 1 and Level 2) are shown in Figure 8 and Figure 9 respectively. Figure 8 show that the material reprocessing and disassembly method and handling have the most influence in the recycling cost with values of $57 \%$ and $41 \%$ respectively. However the investment cost (facilities) has only $3 \%$ influence on the recycling cost.

Meanwhile, Figure 9 shows that the component needing the highest cost for reprocessing was body with $22.2 \%$. This gives a very low value at EOL because this component was built up from several types of material and several types of joining technique. This situation makes them difficult to recycle. Meanwhile, the best components are the electrical items, accessories, lamp and dashboard (3.2\%) because their structure is easy to disassemble and also they can be reused as spare parts.

Again the values that are used are 9-3-1-0. The determination of each value depends on the impact of its contribution to the cost of reprocessing of ELV. For example, seat contributes the high cost for the waste processing because it is containing a lot of foam. So, this will increase the recycling cost (high cost impact, 9). But accessories contribute the low cost for the waste processing. So, the cost impact decided as 1. Meanwhile, for example the dashboard and ferrous have no relationship in the current design, so there is no impact on cost (0).

\subsubsection{Revenue-Cost Ratios}

From the above mentioned two analyses, the overall result can be summarised as shown in Figure 10 (relative value) and Figure 11 (absolute value). Meanwhile, Figure 12 shows the revenue-cost ratios for recycling process of the whole vehicle.

In this process, two main parameters are analysed i.e. revenue at end-of-life and cost for the recycling processes. The detailed analysis for each parameter is based on a two step operation; analysis of key product characteristics compared to the Design for End-of- Life Value requirements and then based on this result, each part or component is analysed to determine the relative revenue (\%) at end-of-life. Based on this results, the absolute revenue (£) can be determined. Meanwhile for the relative cost (\%) for recycling processes, key reprocessing characteristics are compared to the recycling cost requirements and finally each part or component is analysed as for the determination of relative revenue. After that results will be translated into absolute cost $(\mathfrak{E})$. The results from both analysis (absolute values for revenue and cost) are transferred into Revenue-Cost ratios. This ratio clearly shows which component or part of the vehicle has a potential for improvement in order to increase the value at end-of-life and lower recycling costs. The proposed concept is very useful in determination of the performance of a current design.

Referring to Figure 12, there are two components that give a ratio below one. These are glass and tyre. These components have the lowest scores and should take priority in improvement in order to improve the recyclability performance for the whole vehicle.

\subsection{Discussion}

As a summary, this section present the design performance analysis in terms of end-of-life value requirements through RFD analysis. This is the main issues of the proposed methodology. Currently this requirement becomes important factor in vehicle design especially with the introduction of EU Directive on ELV. One of the elements in this Directive is a take back responsibility by vehicle manufacturers. Based on that requirement, automotive 
industries face an extra burden. Besides concentrating to the design process, they also have to consider the logistics for the ELV. Either they recycle with their own facilities or send to recycling company to do it.

Nowadays, these two sectors (vehicle manufacturer and recycling industry) are interrelated to each others. The vehicle designers need information from recyclers especially in terms of revenue and cost for recycling of the vehicle in order to set the design target. The vehicle designers must be change the design target in order to suit the target value from recycling process. Meanwhile, the performance of the recycling process mostly depends on the design of the vehicle itself.

The main objective of this paper is to highlight the development a methodology for Design for End-of-Life Value (DFEL Value) in automotive engineering in order to fulfil the end-of-life legislation, design and economic requirements. This methodology will enable automotive designers to design products that are technically and economically viable for EOL and also act as a strategic decision model for the company.

Basically, the outcomes of this work are the design methodologies. There are design tool, value analysis and investment appraisal. These entire concepts have been developed with a dynamic characteristic in order to handle changes in legislation, cost (materials, processing and reprocessing) and technology and also to be integrated with the current practices of design. In order to demonstrate, verify and validate the proposed methodology, several ELV components are introduced with the intention of investigating the recyclability of the ELV, the optimal quantity of materials removed by the disassembler prior to shredding and also to maintain the maximum return for both the disassembler and shredder.

In this case, weight, cost and revenue are used as a common language to integrate the various levels of the analysis. For this purpose, the vehicle components that have been chosen as a case studies are front bumper, rear bumper, front seat and also the whole vehicle. Several situations are demonstrated including the current design and redesign of the whole vehicle. This is for the purposes of measuring an improvement for each component. In the redesigning process, several cases are considered in order to identify their level of influence in the DFEL Value concept. These are selection of material, method of joining and design of component. This can be used as design guidance for the future development of the vehicle to fulfil the requirements of EU Directive on ELV.

As a general statement, there are three main outcomes of this project; recyclability assessment of the ELV, value analysis for design assessment and also strategic guidance for the company. Based on the early findings in this area, it shows that disassembly and recycling are the two factors that most influence the Design for End-of-Life Value concept in automotive engineering. These two factors must be considered more rigorously in the early product design process. This is in order to make the concept of ELV more successfully implemented and compliant to the EU Directive.

The second finding is a design recyclability assessment tool for the vehicle designing processes using a new approach called Recycling Function Deployment (RFD). RFD is a new idea based on the concept of Quality Function Deployment (QFD). This proposed framework would enable vehicle designers to analyse the recyclability of the vehicle components at the early design stage. On the other hand, the vehicle designers can identify the performance of the vehicle design in terms of recyclability. The results from this analysis become guidance in order to improve the design of that particular component and at the same time to fulfil the EU Directive on ELV.

Current legislation in many European Union (EU) countries is increasingly guided by the originator principle, which means that anyone who inflicts harm on the environment should pay for cleaning up the damage and, in turn, will compel manufacturers to undertake efforts towards recycling at the end-of-life of their products. This has huge implications on the end-user, the manufacturer and recyclers. As such, environmental issues should be accountable throughout the whole life cycle of a product, i.e. its design, manufacture, use, service and its end-of-life. Indeed, it is becoming increasingly important that considerations are given to the disassembly of a product that can allow complete material recycling, along with possible part and subassembly reuse.

Throughout the development of the methodology, two industrial visits were performed. A visit to shredding company was carried out in order to gain an in-depth knowledge of the shredding process. The visit highlighted numerous issues and areas of concern relating to the shredding process. It is clear how complex it is and how hard it is to separate the ELV into its different materials. The second field trip was to a dismantling company. Again this trip provided an insight into the dismantling process and the various issues associated with it. It is an industry which is massively complex. It is believed that the only ways to dismantle vehicles to get some value from its components are in using advanced tools and techniques. The largest contribution to the dismantling processes is an implementation of design methods at the early stage of vehicle design such as design for disassembly (DFD), design for environment (DFE), design for recycling (DFR) etc. In order to increase the performance of ELV, a 
careful planned strategy is required in the design process. Vehicle manufacturers must continue to incorporate reuse, remanufacturing and recycling into the design of new vehicles. Using the recovered materials must be a high priority besides the others factors such as types of joining, product structure etc.

Overcoming the challenge to improve the recyclability of ELV will require the proper design methodology with full dedication from the key players involved in the designing process of vehicles. As mentioned above, environment issues have become a high priority for each company. This has involved everybody, the user and also the manufacturers. In order to tackle this issue, everyone will grapple with problems of profitability, quality, innovation, price and all other aspects of contemporary economic life. It has become more complex to decide what makes a vehicle environmentally friendly.

However, it would seem simple for automotive manufacturers to meet the recycling targets set by the EU Directive, as many have are already $75 \%$ of components recycled. But in reality, the $75 \%$ that is currently recycled is the metallic materials because they are profitable. The remaining $25 \%$ is made from plastics, fluids, glasses etc. that is currently disposed of in landfill sites. That is the real problem faced by the sector.

Automotive manufacturers have to meet the two main types of attributes in developing a new vehicle i.e. functional attributes and environmental attributes. The functional attributes are the main function of the vehicle such as safety, styling, appearance, technology etc. Basically, this is the internal problem that happens within the company itself. Meanwhile, the environmental attributes address global issues such as legislation, emissions, recycling target etc.

The object of trade-off with functional and environmental demand is to evaluate the benefit and cost of alternatives so that the most appropriate parameters can be selected for implementation. In this case, three environmental attributes have been considered for the development of the proposed methodology. These are Directive consideration, DFEL Value and recycling cost requirements. These requirements have to be fulfilled so that the vehicle can be claimed to be designed for end-of-life. To ensure that the EU Directive is met, all these requirements are cascaded to the development of each single component. In general, to assist meeting these requirements, two areas have to be focused on and reviewed during the vehicle development process. These are design for environment (DFE) and end-of-life vehicles (ELV).

DFE is a systematic approach to improving the environmental performance of vehicles over their entire life. This ensures the environmental issues are considered at the initial design phase and considers all the different aspects of a vehicle component that will have an environmental impact. Meanwhile the ELV concept which was the subject of this reported research is to ensure vehicle components can be recycled and dismantled easily at end-of-life. Again these issues will be considered at the early design stage.

\section{Conclusion}

The framework for Design for End-of-Life Value presents the design assessment for the recyclability of the vehicle at the initial design stage. It assist automotive designers to identify the performance of the current design in terms if costs and revenue at EOL. The result from the analysis also can use as guidance in order to improve the performance of the vehicle design in terms of recyclability aspects and at the same time to fulfil the EU Directive on ELV.

The case study presented shows that the current design of that product has some value for recyclability. The developed framework is a tool to increase interaction between the automotive designers and the recycling companies and also as a foundation for the business strategy.

However, further study will carried-out in development of a methodology for the design improvement. This is to provide a guidance and justification on how the vehicle components should be developed.

\section{References}

APME Report. (2003). Recovery Options for plastic Parts from End-of-Life Vehicle: an Eco-efficiency Assessment. Association of Plastics Manufacturers in Europe, Belgium.

Afrinaldi, F., Mat Saman, M. Z., \& Mohamed Shaharoun, A. (2010). EDAS: Software for End-of-Life disassembly analysis. International Journal Sustainable Design, 1 (3), 257-277. http://dx.doi.org/10.1504/IJSDES.2010.036971

Alting, L., \& Jorgensen, J. (1993). The Life Cycle Concept as a Basis for Sustainable Industrial Production. Annals of CIRP, 42, (1), 163-167. http://dx.doi.org/10.1016/S0007-8506(07)62417-2

Dieffenbach, J. R., Mascarin, A. E., \& Fisher, M. M. (1993). Cost Simulation of the Automobile Recycling Infrastructure: The Impact of Plastics Recovery. SAE Paper, pp. 45-52. http://dx.doi.org/10.4271/930557 
Directive 2005/673/EC of the European Parliament and of the Council on End-of-Life Vehicles. (2005). EU.

Directive 2000/53/EC of the European Parliament and of the Council on End-of-Life Vehicles. (2000). EU.

DTI Report. (2003). End of Life Vehicle (ELV) Waste Arising and Recycling Rates. [Online] Available: http://www.dti.gov.uk/ (September 19, 2004)

Ferrao, P., \& Amaral, J. (2006). Assessing the Economics of Auto Recycling Activities in Relation to European Union Directive on End-of-Life Vehicles. International Journal of Technological Forecasting and Social Change, 73, 277-289. http://dx.doi.org/10.1016/j.techfore.2004.03.010

Goodfellow, M. (2002). EU's End-of-Live Vehicle Rules Stuck in Neutral. Environmental Finance, April, UK.

Halog, A., Schultmann, F., \& Rentz, O. (2001). Using Quality Function Deployment for Technique Selection for Optimum Environmental Performance Improvement. Journal of Cleaner Production, 9 (5), 387-394. http://dx.doi.org/10.1016/S0959-6526(00)00080-9

Hassan, M. F., Saman, M. Z. M., Sharif, S., \& Omar, B. (2011). Methodology for Sustainable Product Design: A Review and Direction of Research. Proceeding of International Conference Mechanical and Manufacturing Engineering, 6-8 June 2011, Putrajaya, Malaysia.

Joshi, K., Venkatachalam, A., \& Jawahir, I. S. (2006). A New methodology for transforming 3R concept into 6R concept for improved product sustainability, Paper Presented at the IV Global Conference on Sustainable Product Development and Life Cycle Engineering. 3-6 October, São Carlos, Brazil.

Kimberley, W., \& Glover, M. (2004). Recycling: Force to Strip. Automotive Engineer (pp. 26-27), July/August, UK.

Mat Saman, M. Z., Afrinaldi, F., Zakuan, N., Blount, G., Goodyer, J., Jones, R., \& Jawaid, A. (2010). Strategic guidance model for product development in relation with recycling aspects for automotive products. Journal of Sustainable Development, 3 (1), 142-158.

Masui, K., Sakao, T., Kobayashi, M., \& Inaba, A. (2003). Applying Quality Function Deployment to Environmentally Conscious Design. International Journal of Quality and Reliability Management, 20 (1), 90-106. http://dx.doi.org/10.1108/02656710310453836

Mercedes Magazine. (2002). From Cradle to Cradle (pp. 47-50).

Kwak M. J., Hong Y, S., \& Cho N. W. (2009). Eco-Architecture Analysis for End-of-Life Decision Making. International Journal of Production Research, $47 \quad$ (22), $6233 \quad$ - 6259. http://dx.doi.org/10.1080/00207540802175329

Santos-Reyes, D. E., \& Lawlor-Wright, T. A. (2001). A Design for the Environment Methodology to Support an Environment Management System. Journal of Integrated Manufacturing System, 12 (5), 323-332. http://dx.doi.org/10.1108/EUM0000000005710

Tipnis, V. A. (1991). Product Life Cycle Economic Models: Towards a Comprehensive Framework for Evaluation of Environment Impact and Competitive Advantage. Annals of the CIRP, 40 (1). http://dx.doi.org/10.1016/S0007-8506(07)62030-7

Tzafestas, S. G., Anthopoulos, Y., Katevas, N., \& Spyropoulou, E. (1997). Architecture and Implementation of an Autonomous Car-disassembly System. Journal of System Analysis Modelling Simulation, 29 (2), 129-149.

Veerakamolmal, P., \& Gupta, S. M. (1999). A Combinatorial Cost-Benefit Analysis Methodology for Designing Modular Products for the Environment. IEEE International Symposium on Electronic and the Environment (pp. 268-273). 


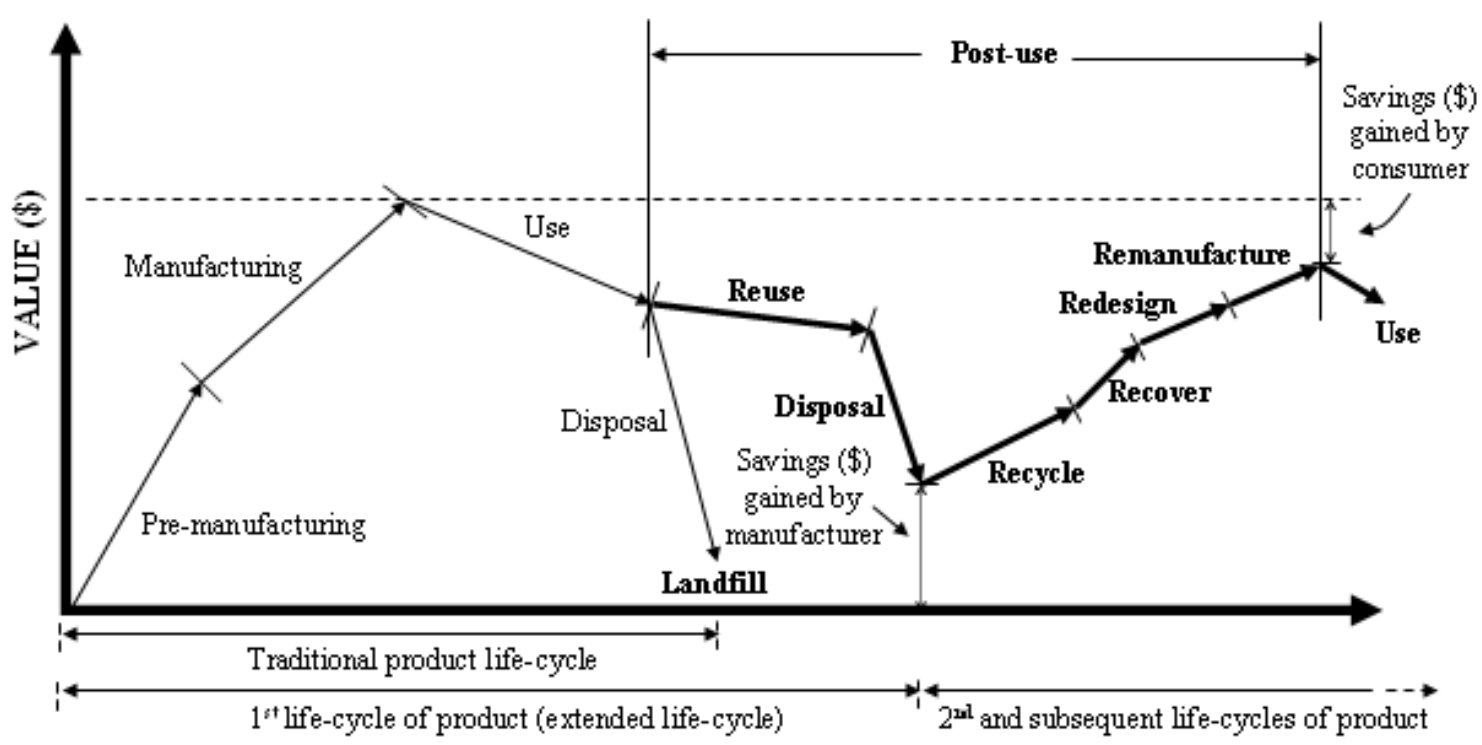

Figure 1. Product value gained from 6R (Joshi et al., 2006)

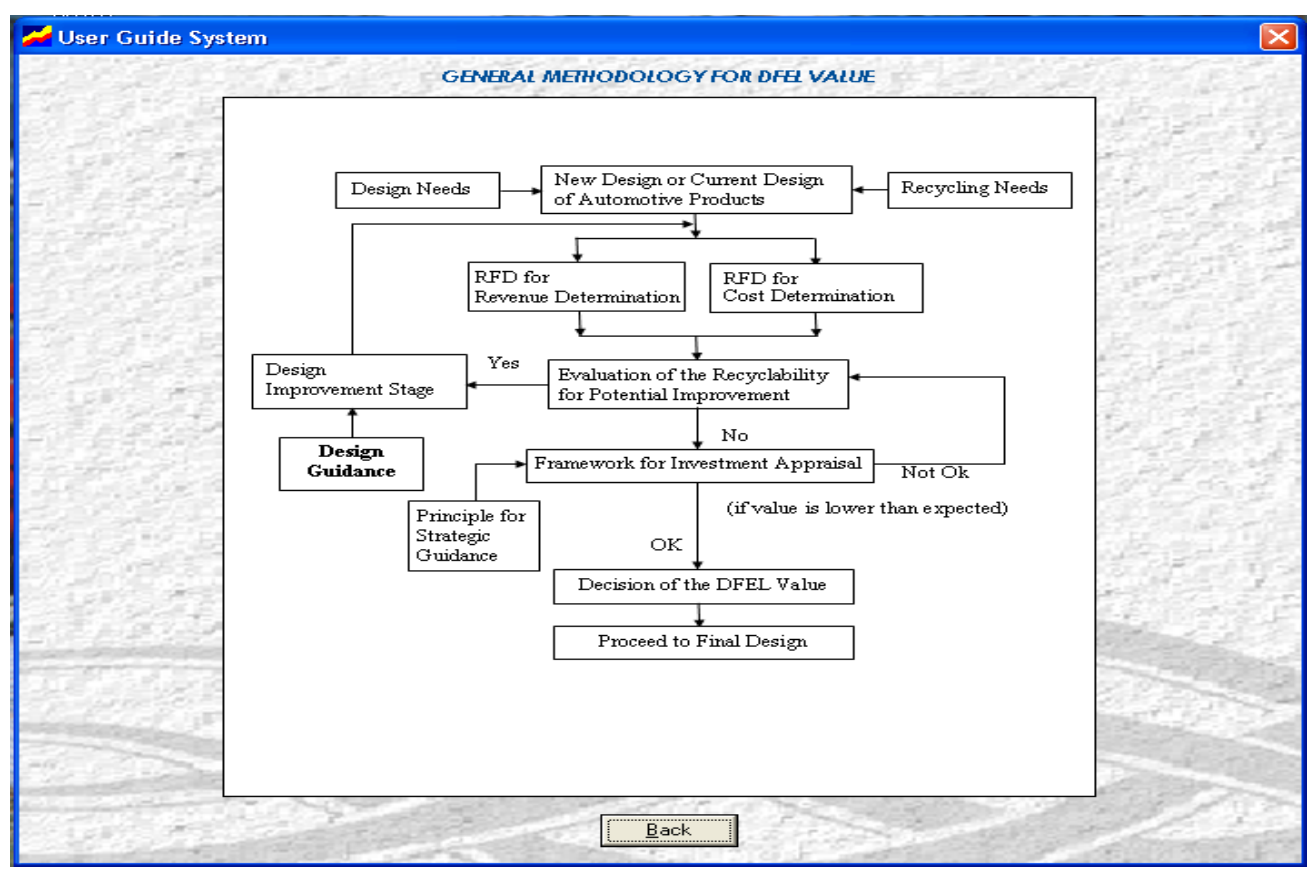

Figure 2. Principle of study methodology for DFEL Value 


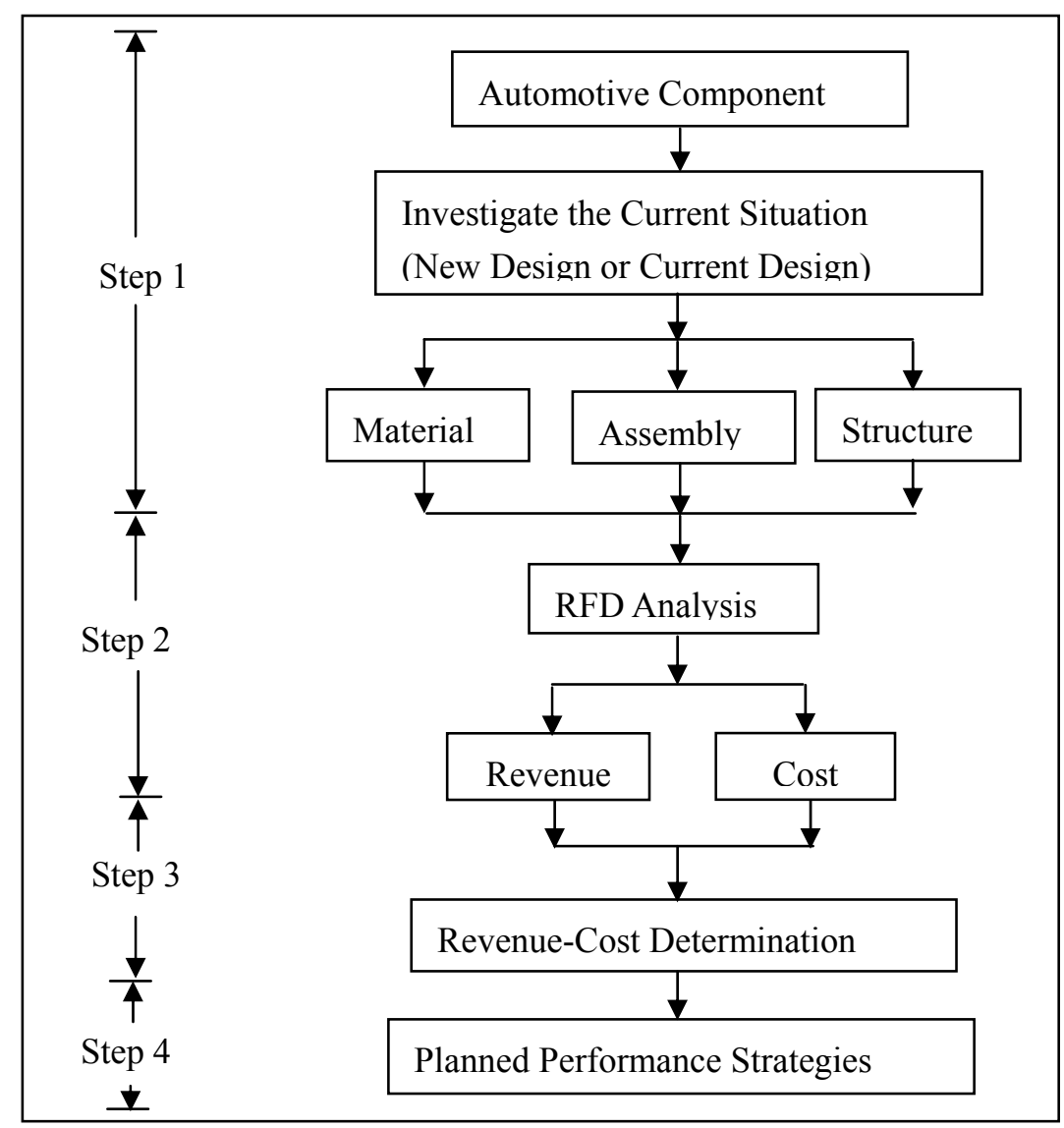

Figure 3. General processes for RFD analysis 


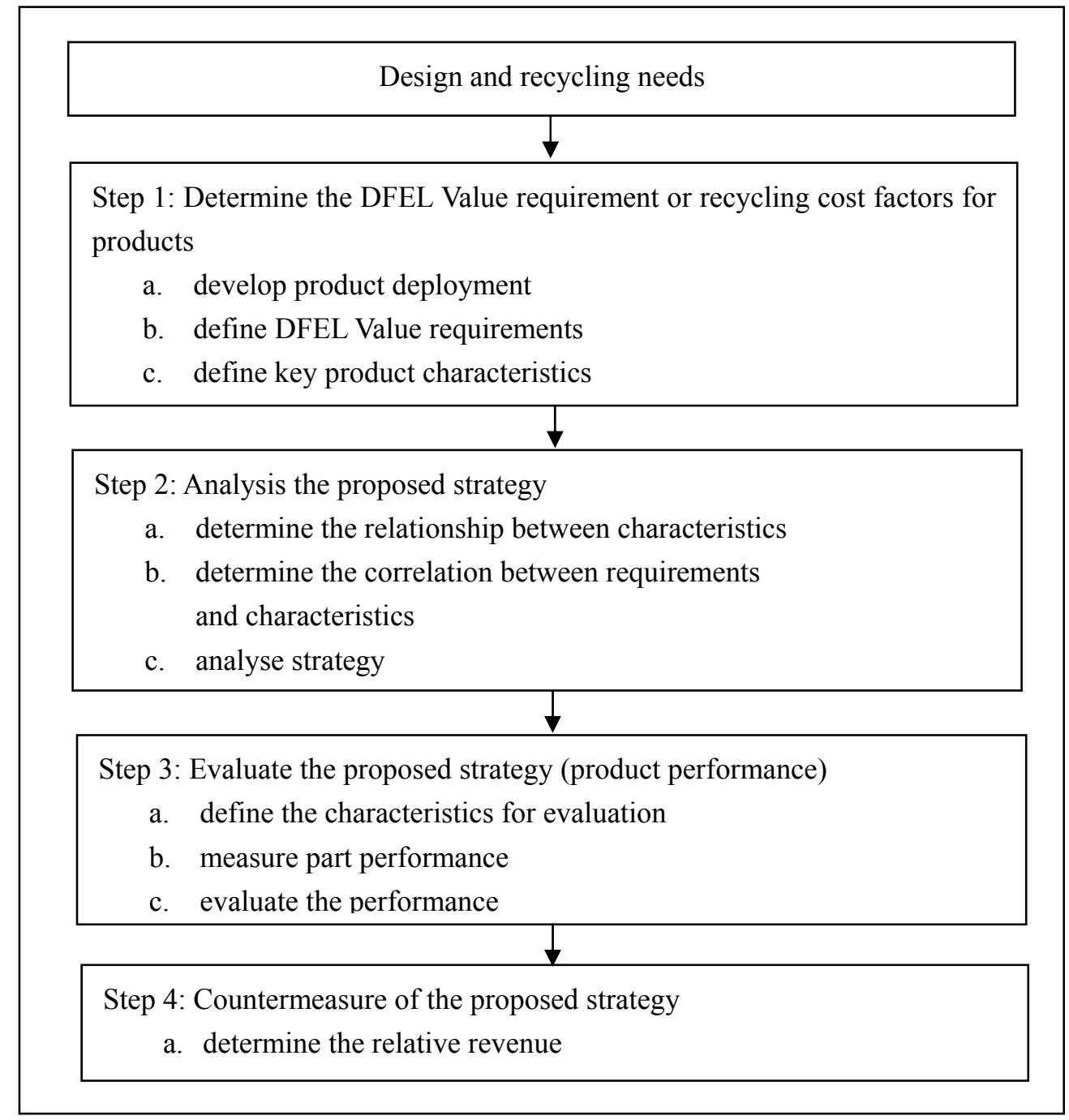

Figure 4. Detail for revenue determination and cost determination

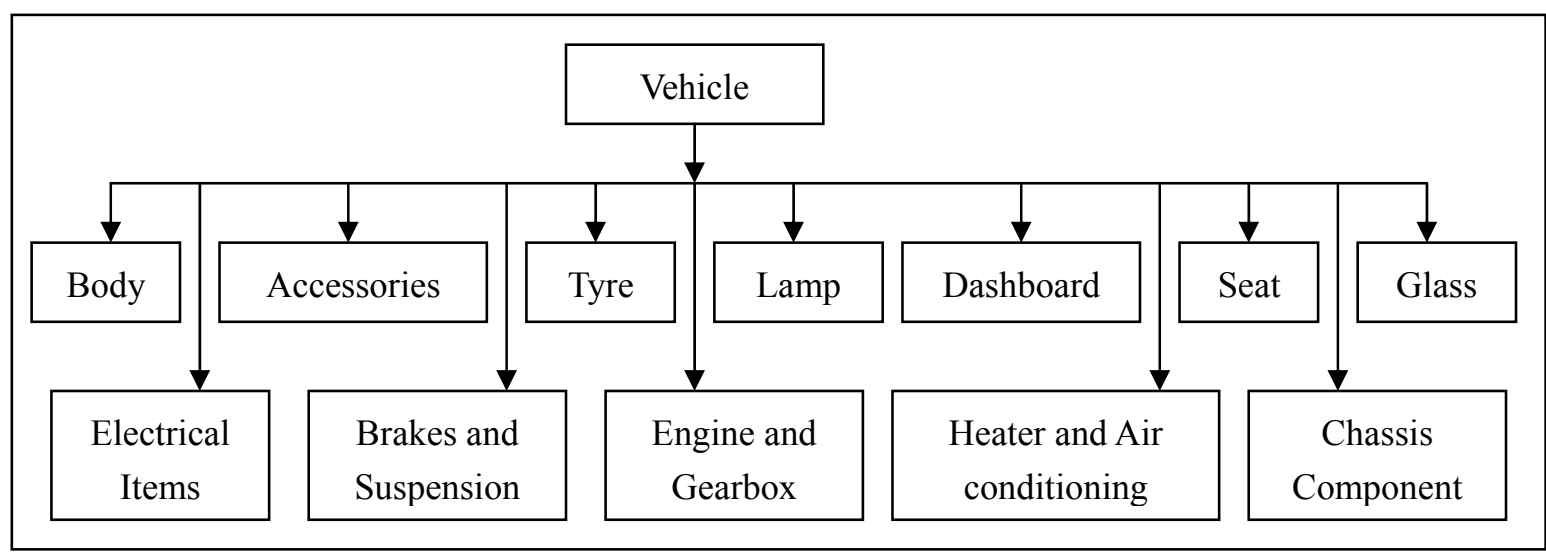

Figure 5. Product structure for the vehicle 


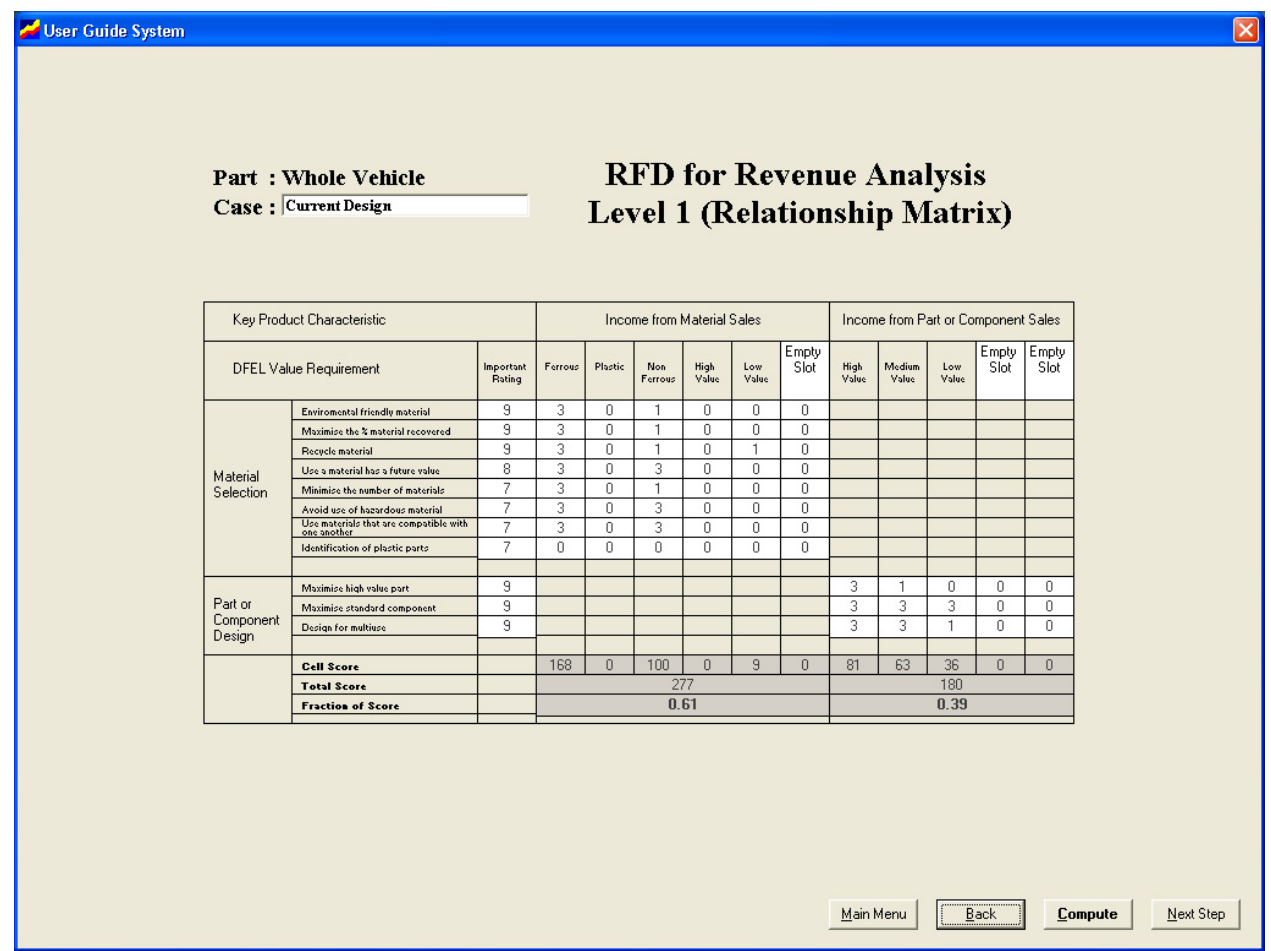

Figure 6. Result of Level 1(Revenue Determination)

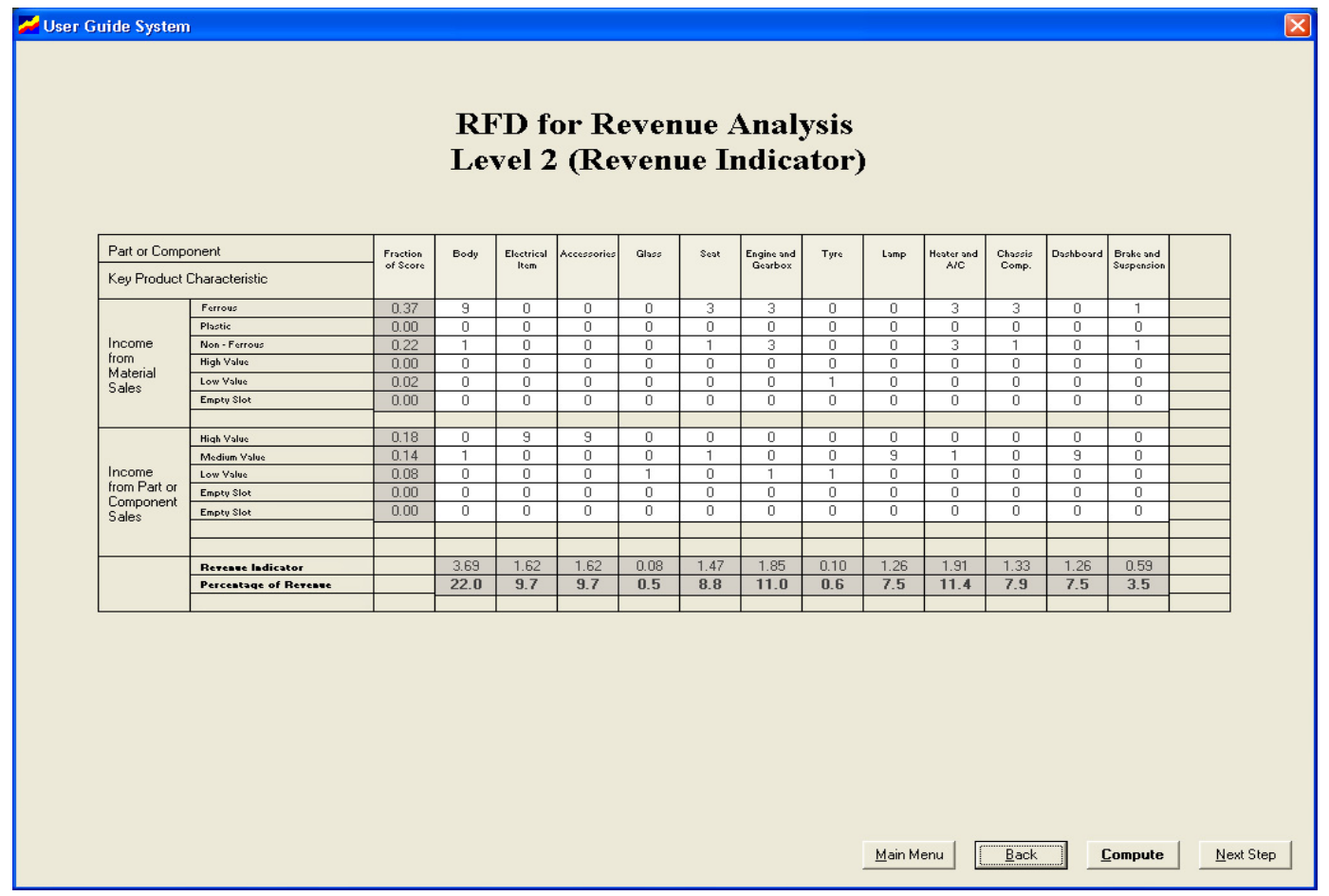

Figure 7. Result of Level 2 (Revenue Determination) 


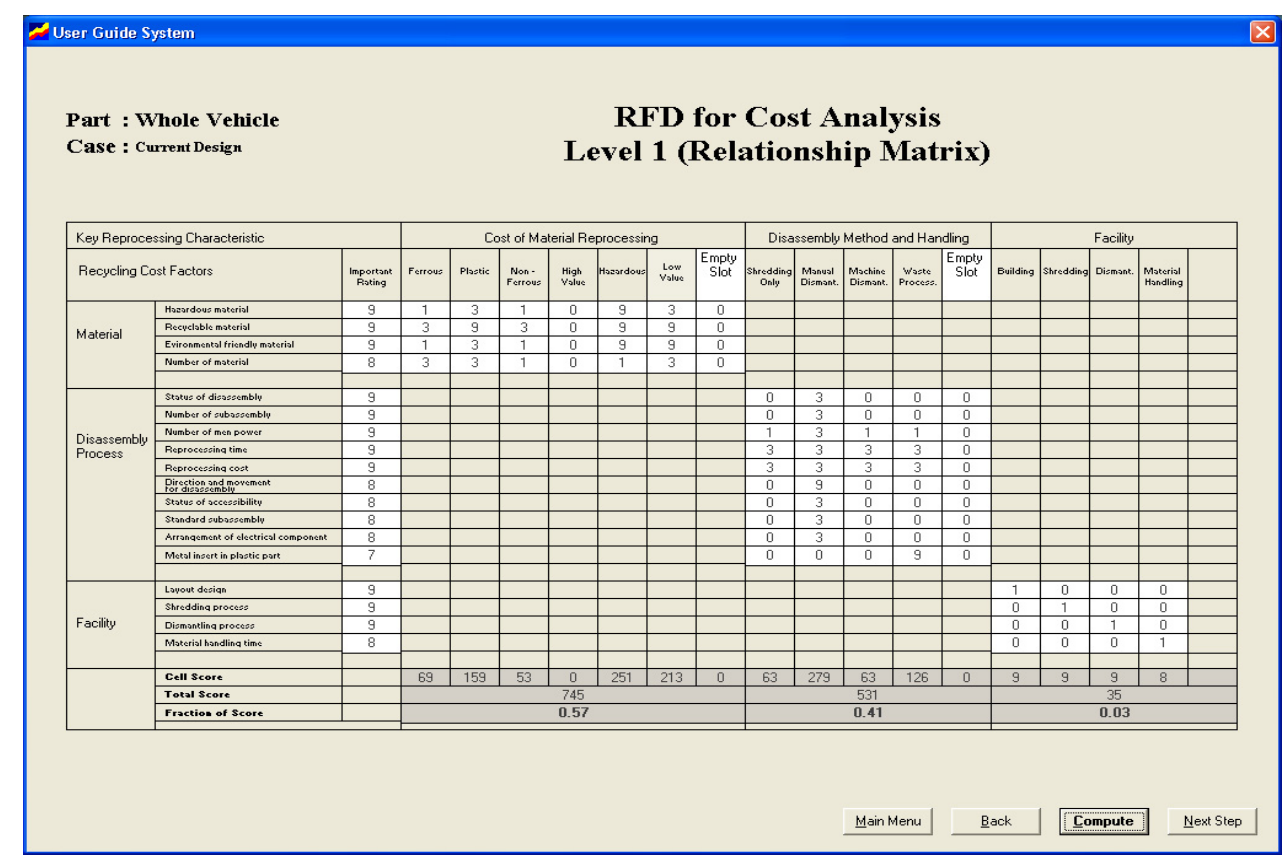

Figure 8. Result of Level 1 (Cost Determination)

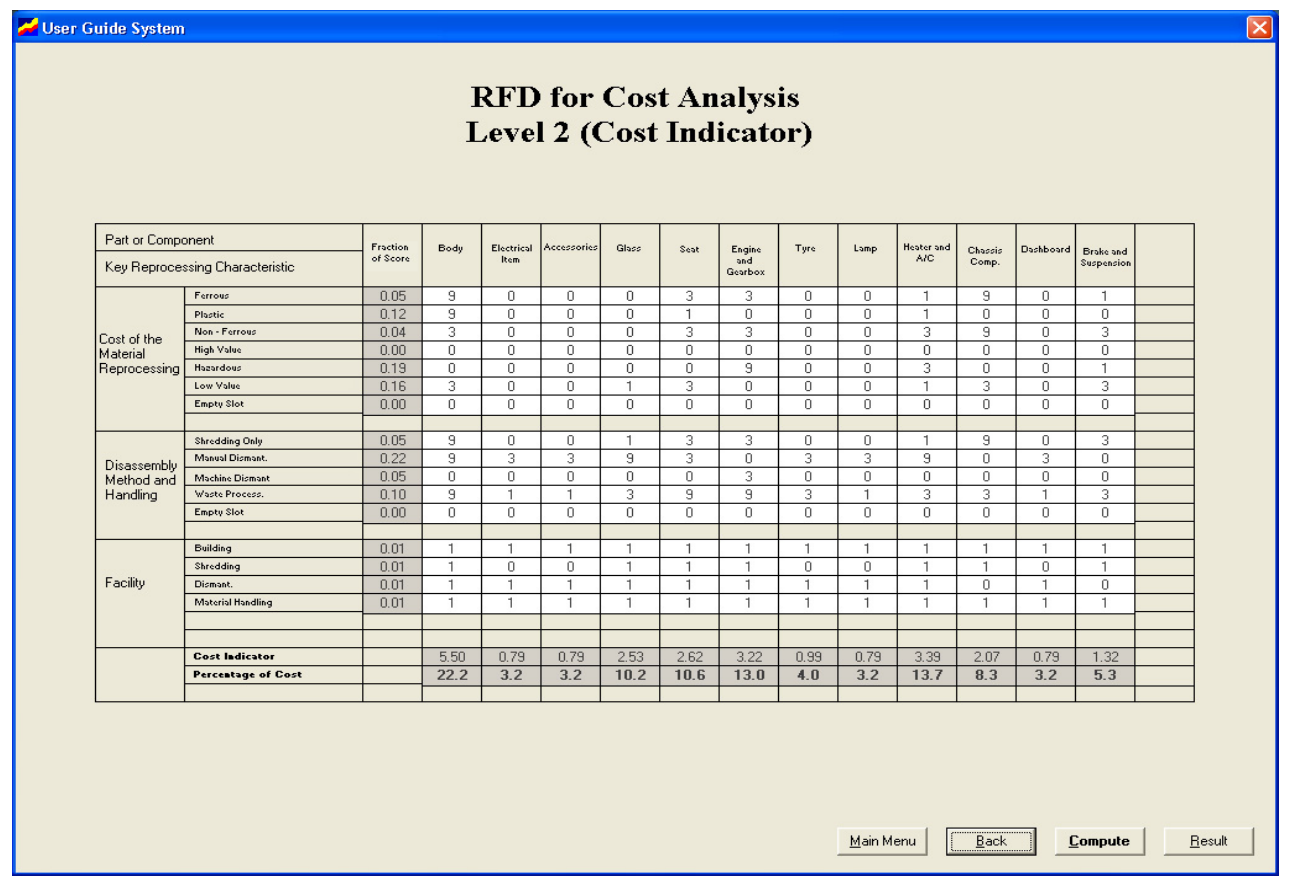

Figure 9. Result of Level 2 (Cost Determination) 


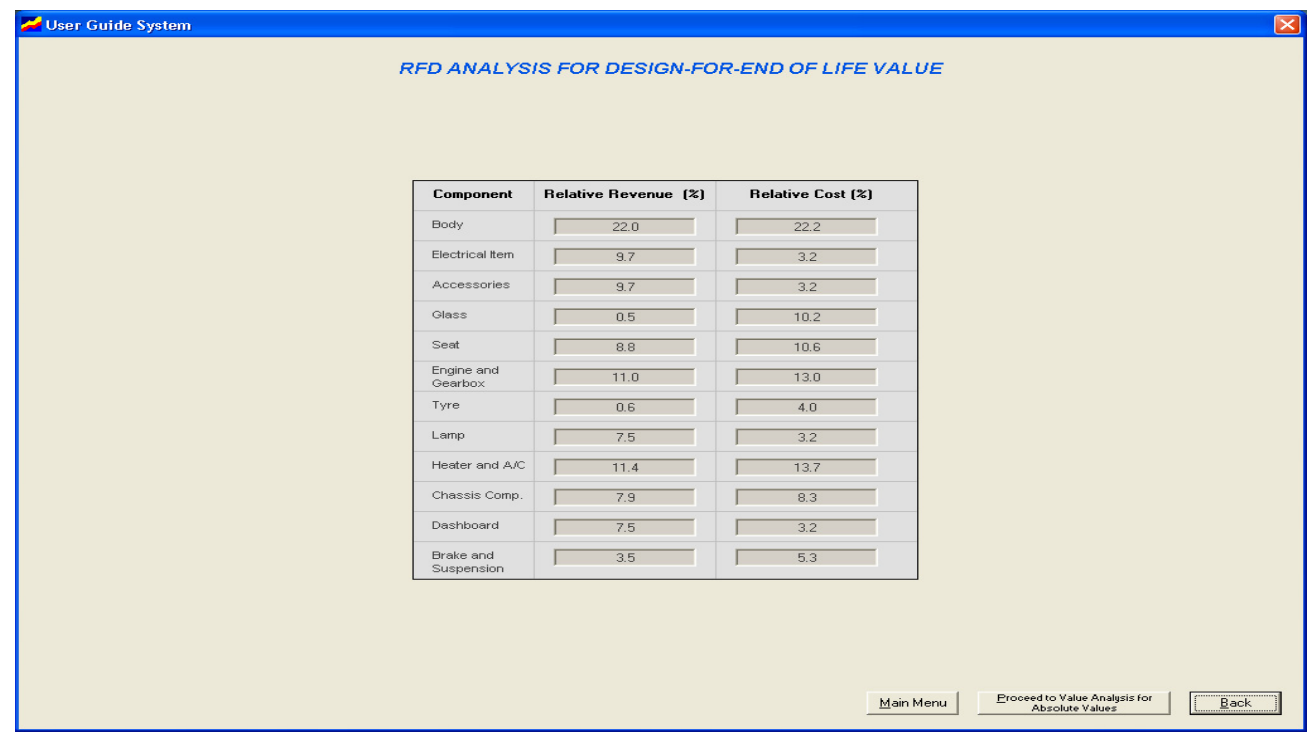

Figure 10. The relative results for whole vehicle

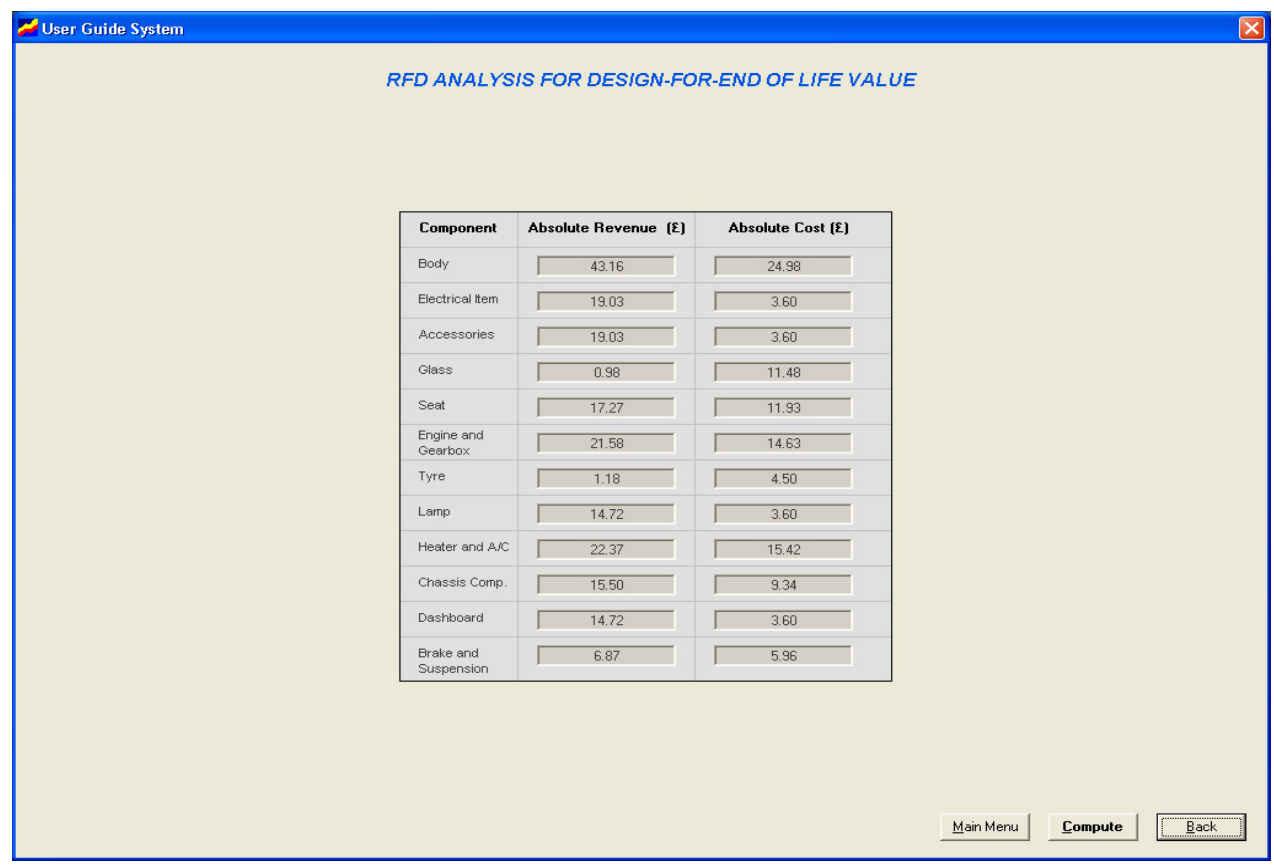

Figure 11. The absolute results for whole vehicle 
RFD ANALYSIS FOR DESIGN-FOR-END OF LIFE VALUE

\begin{tabular}{|c|c|c|}
\hline Component & Revenue - Cost Ratio & Performance \\
\hline Body & 1.73 & \\
\hline Electrical them & 5.29 & \\
\hline Accessories & 5.29 & \\
\hline Glass & 0.09 & Need Possible Improvement \\
\hline Seat & 1.45 & \\
\hline $\begin{array}{l}\text { Engine and } \\
\text { Gearbox }\end{array}$ & 1.48 & \\
\hline Tyre & 0.26 & Need Possible Inprovement \\
\hline Lamp & 4.09 & \\
\hline Heater and $A / C$ & 1.45 & \\
\hline Chasis Comp. & 1.66 & \\
\hline Dashboard & 4.09 & \\
\hline $\begin{array}{l}\text { Brake and } \\
\text { Suspension }\end{array}$ & 1.15 & \\
\hline
\end{tabular}

\begin{tabular}{l|l|l|} 
Main Menu & Weakness & Design Advice \\
\hline
\end{tabular}

Back

Figure 12. The revenue-cost ratios for recycling process of whole vehicle 